BBA 31767

\title{
DIMERIZATION OCCURS DURING THE REVERSIBLE ACID INACTIVATION OF 2-OXO-4-HYDROXYGLUTARATE ALDOLASE FROM ESCHERICHIA COLI
}

\author{
HARRY C. WINTER, NEIL D. LEWINSKI, JANET K. WANG * and EUGENE E. DEKKER ** \\ Department of Biological Chemistry, The University of Michigan, Ann Arbor, MI 48109 (U.S.A.)
}

(Received July 5th, 1983)

Key words: 2-Oxo-4-hydroxyglutarate aldolase; Acid inactivation; Dimerization; (E. coli)

Exposure of Escherichia coli 2-oxo-4-hydroxyglutarate aldolase (4-hydroxy-2-oxoglutarate glyoxylate-lyase, EC 4.1.3.16) (molecular weight $=63000$ ) to phosphoric acid at $\mathrm{pH} 1.6$ for $10 \mathrm{~min}$ at $4^{\circ} \mathrm{C}$ causes $95 \%$ or greater inactivation. No significant effect on the rate or extent of inactivation is caused by varied aldolase concentrations or the presence of exogenous proteins. Chloride ion (50-100 mM) or $10 \mathrm{mM}$ 2-oxo-4-hydroxyglutarate markedly decreases both the rate and extent of inactivation; good protection is also afforded by $10 \mathrm{mM}$ pyruvate, glyoxylate, glyoxal, 2-oxoglutarate or 2-oxobutyrate. Whereas native aldolase has two free and three buried sulfhydryl groups, all five are exposed in the acid-inactivated enzyme and the molecular weight of this species at $\mathrm{pH} 1.6$ is $\mathbf{1 2 6 0 0 0}$. Ultraviolet absorbance difference spectra, circular dichroism spectra and ultracentrifugation studies establish that the inactivation process is characterized by an alteration of secondary and tertiary structure as well as an aggregation to a dimer of the native molecule. Reactivation of enzyme activity to 60-80\% of the original level is seen within $20 \mathrm{~min}$ at $\mathrm{pH} 6$ to 8 ; examination of inactivation / reactivation as a function of $\mathrm{pH}$ indicates that these two processes occur via kinetically distinct pathways. Native and reactivated enzymes are identical in molecular weight, sulfhydryl titer, $K_{\mathrm{m}}$ and $\alpha$-helix content.

\section{Introduction}

2-Oxo-4-hydroxyglutarate aldolase (4-hydroxy2-oxoglutarate glyoxylate-lyase, EC 4.1.3.16, 4-hydroxy-2-oxoglutarate $\rightleftharpoons$ pyruvate + glyoxylate $)$ is known to be a central enzyme in the mammalian catabolism of L-hydroxyproline [1]. We have purified this enzyme to homogeneity from extracts of bovine liver [2], bovine kidney [3] and Escherichia coli $\mathrm{K}-12$ [4]. The enzyme from all three sources catalyzes the reaction via a mechanism involving Schiff-base formation between 2-oxo-4-hydroxyglutarate or pyruvate and an active-site lysine re-

\footnotetext{
* Present address: Department of Biochemistry, Southern Illinois University, Carbondale, IL 62901, U.S.A.

** To whom correspondence should be addressed.
}

sidue [5,6], i.e., it is a Class I, 'lysine-type', aldolase. When compared with other Class I aldolases, however, 2-oxo-4-hydroxyglutarate aldolase from all three sources is atypical in that it (a) forms a dead-end or 'abortive' Schiff-base intermediate with glyoxylate $[6,7,3],(\mathrm{b})$ is completely and irreversibly inactivated by cyanide only in the presence of glyoxylate with stable formation of an aminonitrile [8], and (c) is bifunctional, effectively catalyzing the $\beta$-decarboxylation of oxaloacetate as well as the aldol cleavage or formation of 2-oxo-4-hydroxyglutarate $[9,7,3]$.

The enzymic proteins obtained from kidney, liver or $E$. coli also have several different properties. They differ in size $\left(M_{\mathrm{r}}=140000,120000\right.$ and 63000 , respectively) and whereas the kidney and liver enzymes are tetramers, that from $E$. coli has a 
trimeric subunit structure [10]. Also, whereas the kidney and liver aldolase are virtually nonstereospecific in cleaving or forming the optical isomers of 2-oxo-4-hydroxyglutarate, the $E$. coli enzyme is stereoselective toward L-2-oxo-4-hydroxyglutarate. Furthermore, the $\beta$-decarboxylase/aldolase activity ratio varies from 0.22 to 0.50 to 1.00 , respectively, for kidney, liver and $E$. coli aldolase. An interesting system is in hand, therefore, with which to explore detailed enzyme structure/function interrelationships.

In the course of our studies with $E$. coli 2-oxo4-hydroxyglutarate aldolase, we observed that this enzyme was completely inactivated at $\mathrm{pH} \mathrm{1-2} \mathrm{but}$ that, when again neutralized, $60-80 \%$ of the initial activity was recovered. Our findings reported here include the observation that, in contrast to cases where exposure to acid causes dissociation, acid inactivation in this instance is associated with unfolding and dimerization of the enzyme.

\section{Materials and Methods}

Isolation and purification of the aldolase. E. coli K-12 cells were cultured and 2-oxo-4-hydroxyglutarate aldolase was purified by methods already described [4]. Enzyme preparations having a specific activity of approx. 2.5 units $\cdot \mathrm{mg}^{-1}$ and which were essentially homogeneous by polyacrylamide gel electrophoresis at $\mathrm{pH} 9.3$ were used. One unit of activity is defined as the amount of enzyme that catalyzes the formation of $1 \mu \mathrm{mol}$ of glyoxylate $\cdot \min ^{-1}$, as measured colorimetrically [11].

Enzyme assay. Inactivation or reactivation of 2-oxo-4-hydroxyglutarate aldolase was followed spectrophotometrically by coupling the formation of pyruvate with NADH oxidation via lactate dehydrogenase [12]. This procedure was more suitable than the colorimetric assay, since initial rates were determined; errors due to reactivation of inactive enzyme during the assay were thereby minimized. The reaction mixture contained (per $\mathrm{ml}$ ): Tris- $\mathrm{HCl}$ ( $\mathrm{pH} \mathrm{8.4),} 100 \mu \mathrm{mol}$; lactate dehydrogenase, $25 \mu \mathrm{g}$; NADH, $0.166 \mu \mathrm{mol}$; and DL-2oxo-4-hydroxyglutarate, $5 \mu \mathrm{mol}$. Generally, 0.65 $\mathrm{ml}$ of the reaction mixture was used in a $1-\mathrm{ml}$ semimicro cuvette; a decrease in absorbance of 0.1 at $340 \mathrm{~nm}$ represented oxidation of $0.01 \mu \mathrm{mol}$ of
NADH, assuming a millimolar extinction coefficient of 6.3 [13].

Enzyme inactivation and reactivation. Loss of aldolase activity under acidic conditions was followed either by diluting a small aliquot of the stock enzyme solution with a buffer of desired $\mathrm{pH}$, or by adding a predetermined volume of $43 \%$ phosphoric acid. Aliquots of such solutions were withdrawn at fixed intervals of time and rapidly mixed with the assay components $(0.65 \mathrm{ml})$; absorbance changes were followed with a Gilford spectrophotometer thermostatted at 20 or $37^{\circ} \mathrm{C}$. The initial rate of NADH oxidation constituted a measure of aldolase activity. Buffering capacity of the assay mixture was sufficient to maintain the $\mathrm{pH}$ regardless of the acidity of the enzyme solution added.

Similarly, reactivation of enzymic activity was accomplished either by diluting the acid-inactivated enzyme solution with a suitable buffer, or by adding a predetermined volume of $\mathrm{KOH}$ solution to provide the desired $\mathrm{pH}$. Regain of aldolase activity was determined by assaying aliquots of the solution as before.

Measurements with the ultracentrifuge. The molecular weight of various forms of the enzyme was determined by sedimentation equilibrium centrifugation [14] using a Spinco AN-E rotor in a Beckman Model E ultracentrifuge equipped with interference optics. Sucrose gradients (5 to 20\%) were used for sedimentation velocity measurements in a Beckman SW 50.1 rotor and L3-50 ultracentrifuge. Runs were carried out for $24 \mathrm{~h}$ after which time the tubes were punctured at the bottom and fractions collected. Levels of $280 \mathrm{~nm}$ absorbance and aldolase activity were determined in such fractions. $s$ values were estimated from standard proteins run under identical conditions.

Molecular size determinations by Sephadex chromatography. The molecular size of native, acid-inactivated, and reactivated aldolase was also estimated by chromatography on a calibrated column of Sephadex G-150 [15] at pH 3.3 in $50 \mathrm{mM}$ potassium phosphate buffer containing $20 \mathrm{mM}$ $\mathrm{KCl}$. Enzyme previously inactivated at low $\mathrm{pH}$ $(<2)$ and salt concentration did not regain any activity under these conditions. Ovalbumin, conalbumin and chymotrypsinogen ( $2 \mathrm{mg}$ each) were used as standards, as they retained their native 
molecular weight under these experimental conditions. Chromatography was carried out at $4^{\circ} \mathrm{C}$ and the elution profile of proteins was monitored at $280 \mathrm{~nm}$.

Determination of sulfhydryl groups. Free and 'buried' sulfhydryl groups were determined by titration with $p$-mercuribenzoate [16]. A known amount (approx. $0.2 \mathrm{mg}$ ) of enzyme was titrated in a volume of $1 \mathrm{ml}$ with $p$-mercuribenzoate solution (approx. $0.2 \mathrm{mM}$ ) standardized by its absorbance at $233 \mathrm{~nm}\left(E_{1 \mathrm{~cm}}=16.9 \cdot 10^{3}\right)$. In the range of $\mathrm{pH}$ 4 to 7 , titrations were followed at $250 \mathrm{~nm}$, while at $\mathrm{pH} 2.5$ and below they were done at $260 \mathrm{~nm}$. Between pH 2.5 and 4, p-mercuribenzoate undergoes slow spectral changes, especially in the presence of phosphate, so titrations were not performed in that range. When the end-point of a titration was observed, $0.1 \mathrm{ml}$ of a $10 \%$ SDS solution was added and the titration was continued. All readings were corrected for dilution and for the absorbance of unreacted $p$-mercuribenzoate.

Titrations were also carried out on standard solutions of dithiothreitol and reduced glutathione. End-points were observed at 97 and 105\% of the calculated value for dithiothreitol and at about $90 \%$ for glutathione.

Ultraviolet and CD spectral measurements. U1traviolet difference spectra were determined in double-sectioned difference cells using a Cary 15 spectrophotometer. Native enzyme and acidic buffer solutions were placed in reference and sample cells and a baseline was recorded. Subsequently, the sample cell was mixed by inverting several times and the difference spectrum of mixed vs. the unmixed reference cell was then recorded. Accuracy of pipetting and constancy of baseline absorption were frequently checked.

The kinetics of spectral changes as a function of $\mathrm{pH}$ or temperature were followed at the peaks of the difference spectrum; measurements were made with a Gilford spectrophotometer equipped with an automatic cuvette changer. Acid inactivation of the aldolase was accomplished as before. The final $\mathrm{pH}$ of the mixture was verified after the experiment by direct measurement.

The CD spectrum of 2-oxo-4-hydroxyglutarate aldolase was measured in a Jasco Model ORD/ UV-5 spectropolarimeter with a Sproul SS-20 CD modification. For near ultraviolet $(250-350 \mathrm{~nm})$ measurements, a concentration of approx. $0.2 \mathrm{mg}$ of aldolase $/ \mathrm{ml}$ in a $10-\mathrm{mm}$ cuvette with an instrument sensitivity of 2 millidegrees/ $\mathrm{cm}$ was used. Far ultraviolet $(200-250 \mathrm{~nm})$ measurements were performed with approx. $0.01 \mathrm{mg}$ of aldolase $/ \mathrm{ml}$ in a 1-mm cuvette with an instrument sensitivity of either 2 or 5 millidegrees $/ \mathrm{cm}$. The mean residue dichroism of the average of 3 to 4 scans was computed at 1- or 2-nm intervals and replotted. A mean residue weight of 103 , calculated from the amino acid composition [10], was used in the computation.

Protein assays. The concentration of protein in solution was determined either by the method of Lowry et al. [17], of Bradford [18] by binding of Coomassie blue, or from the absorbance at 280 nm. In all these methods, a sample of $E$. coli 2-oxo-4-hydroxyglutarate aldolase which had been dialyzed exhaustively against water and subsequently lyophilized was used as the primary standard; bovine serum albumin served as a secondary standard for the Lowry and Bradford methods. The $E_{1 \%}^{280}$ of the native enzyme was 7.8. Absorbance measurements at $280 \mathrm{~nm}$ as a measure of protein content were used quite selectively, since spectral changes occurred at and around this wavelength when the aldolase was subjected to conditions of acid denaturation.

Materials. 2-Oxo-4-hydroxyglutaric acid was prepared from 4-hydroxyglutamic acid as previously described [11]. Dithiothreitol, lactate dehydrogenase (rabbit muscle or bovine heart), and $p$-mercuribenzoate were obtained from Sigma Chemical Co., P.O. Box 14508, St. Louis, MO 63178, U.S.A.; bovine serum albumin from Pentex Biochemicals, Kankakee, IL 60901, U.S.A.; and sequanal-grade SDS from Pierce Chemical Co., P.O. Box 117, Rockford, IL 61105, U.S.A Coomassie brilliant blue, ovalbumin, conalbumin, chymotrypsinogen and human hemoglobin were purchased from Schwarz/Mann, Inc., Spring Valley, NY 10977, U.S.A. All other chemicals were of the highest purity commercially available. 


\section{Results}

Acid inactivation and reactivation of aldolase activity

When $E$. coli 2-oxo-4-hydroxyglutarate aldolase is subjected to an acidic environment of $\mathrm{pH} 1.6$ in phosphate buffer at $4^{\circ} \mathrm{C}$, a rapid loss of activity occurs (Fig. 1). Activity loss is virtually complete within $10 \mathrm{~min}$ under these experimental conditions, but if the enzyme assay is performed at $\mathrm{pH}$ 8.4 and $37^{\circ} \mathrm{C}$ (i.e., the normal optima) the inactivated enzyme catalyzes an apparent initial rate of reaction about $10 \%$ that of native enzyme. At the start of an assay at a temperature of $20^{\circ} \mathrm{C}$, however, virtually no activity is manifested by the acid-treated aldolase, but with time the enzyme is reactivated and attains approx. $50-60 \%$ of the original level of activity. At the higher assay temperature of $37^{\circ} \mathrm{C}$, some reactivation must occur within the time required to mix the solution (approx. 5-10 s). Restoration of aldolase activity (60-80\% of the initial level) can also be accomplished by first neutralizing the enzyme solution and immediately raising its temperature to $25^{\circ} \mathrm{C}$;

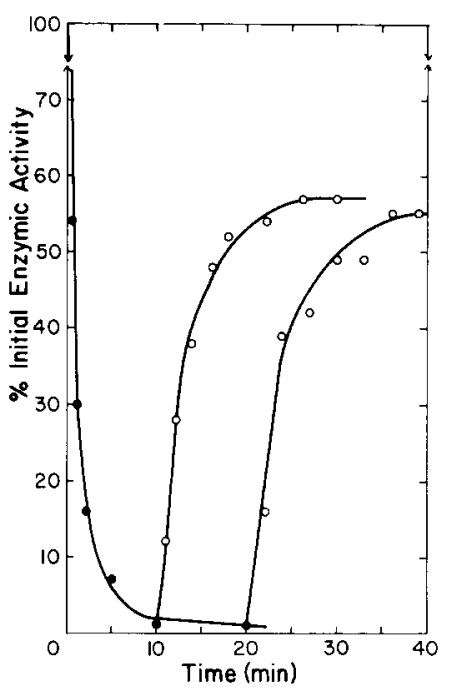

Fig. 1. Time course for the acid inactivation and subsequent reactivation of $E$. coli 2-oxo-4-hydroxyglutarate aldolase. For inactivation, enzyme solution at $4^{\circ} \mathrm{C}$ was acidified to $\mathrm{pH} 1.6$ with $43 \%$ phosphoric acid. To reactivate, the acid-treated solution was neutralized to $\mathrm{pH} 7.0$ with $\mathrm{KOH}$ solution and promptly brought to $25^{\circ} \mathrm{C}$. In each case, aliquots were removed and assayed at $20^{\circ} \mathrm{C}$ as described in the text. The curves shown were obtained by following the rate of absorbance change at $340 \mathrm{~nm}$.

\section{TABLE I}

EFFECT OF SUBSTRATES AND SUBSTRATE ANALOGS ON ACID INACTIVATION AND REACTIVATION OF E. COLI 2-OXO-4-HYDROXYGLUTARATE ALDOLASE

Each compound, at the concentration indicated, was added to the enzyme solution immediately prior to acidifying to $\mathrm{pH} 1.6 \mathrm{with} 43 \%$ phosphoric acid at $4^{\circ} \mathrm{C}$. The acid-inactivated solution was subsequently neutralized to $\mathrm{pH} 7.0$ with $\mathrm{KOH}$ solution and immediately brought to $25^{\circ} \mathrm{C}$. Inactivation is expressed as percent of initial activity remaining after $15 \mathrm{~min}$ at $\mathrm{pH} 1.6$ and $4^{\circ} \mathrm{C}$. Reactivation is expressed as maximum percent of initial activity recovered after $15 \mathrm{~min}$ at $\mathrm{pH} 1.6$ and $4^{\circ} \mathrm{C}$, followed by neturalization to $\mathrm{pH} 7.0$ at $25^{\circ} \mathrm{C}$

\begin{tabular}{|c|c|c|c|}
\hline Substrate or analog added & $\begin{array}{l}\text { Concentration } \\
(\mathrm{mM})\end{array}$ & $\begin{array}{l}\text { Extent } \\
\text { of enzyme } \\
\text { inactivation }\end{array}$ & $\begin{array}{l}\text { Extent } \\
\text { of enzyme } \\
\text { reactivation }\end{array}$ \\
\hline None & - & 8 & 65 \\
\hline \multirow[t]{2}{*}{ 2-Oxo-4-hydroxyglutarate } & 1 & 57 & 95 \\
\hline & 10 & 82 & 100 \\
\hline \multirow[t]{2}{*}{ Pyruvate } & 2 & 21 & 85 \\
\hline & 10 & 40 & 90 \\
\hline \multirow[t]{2}{*}{ Glyoxylate } & 1 & 11 & 95 \\
\hline & 10 & 25 & 82 \\
\hline \multirow[t]{2}{*}{ Glyoxal } & 1 & 15 & 67 \\
\hline & 10 & 25 & 75 \\
\hline 2-Oxoglutarate & 10 & 14 & 60 \\
\hline 2-Oxobutyrate & 10 & 55 & 100 \\
\hline
\end{tabular}


the rate of reactivation is routinely somewhat slower than the inactivation.

The rate and extent of reactivation are unchanged after maintaining the enzyme at $\mathrm{pH} 1.6$ for $24 \mathrm{~h}$. Inability to restore complete aldolase activity, therefore, does not appear to be a function of slow irreversible denaturation of the enzyme in acid solution (e.g., hydrolysis of some uniquely sensitive peptide bond). The only way we have been able to achieve complete recovery of activity is by subjecting the enzyme to reactivation conditions prior to complete loss of activity, where the rate of inactivation is slowed either by high salt concentration, the presence of substrates, or the use of an intermediate $\mathrm{pH}$ for inactivation (see below).

Protection against acid inactivation by substrates. As shown in Table I, substrates of the reaction and certain substrate analogs protected enzymic activity against acid inactivation. The addition of $10 \mathrm{mM}$ 2-oxo-4-hydroxyglutarate, for example, slowed the inactivation process so that after 15 $\min 82 \%$ of the initial enzymic activity was still present and this decreased to only $65 \%$ after 80 min. Neutralization of the assay mixture, after exposure to acid conditions for $15 \mathrm{~min}$ with 10 $\mathrm{mM}$ 2-oxo-4-hydroxyglutarate present, allowed for $100 \%$ recovery of initial aldolase activity. 2-Oxo4-hydroxyglutarate was the most effective of the compounds tested. Pyruvate and glyoxylate were similar to each other in this regard but did not protect quite as well as 2-oxo-4-hydroxyglutarate.

Addition of substrates alone to the enzyme after acid inactivation had proceeded to completion caused no reactivation and did not affect the rate or extent of subsequent reactivation, indicating that the active site of the acid-inactivated aldolase was nonfunctional, with no affinity for substrates or substrate analogs.

Effect of ions on inactivation and denaturation. Chloride ion significantly decreased both the rate and extent of acid inactivation of aldolase activity (Fig. 2). The associated cation also seemed to have some effect, since $\mathrm{NaCl}, \mathrm{KCl}$ and $\mathrm{ZnCl}_{2}$ were approx. $20 \%$ more effective than Tris- $\mathrm{HCl}$ at the same $\mathrm{Cl}^{-}$concentration. $\mathrm{MgCl}_{2}$ was more effective; in the presence of $10 \mathrm{mM} \mathrm{MgCl}_{2}$, the enzyme retained $90 \%$ of its initial activity after exposure to acid treatment for $40 \mathrm{~min}$. However, addition of

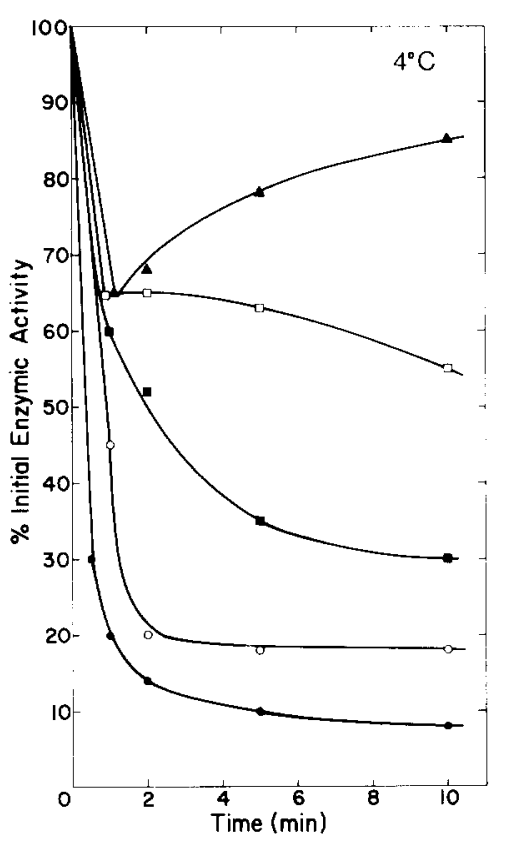

Fig. 2. Effect of chloride ion on acid-inactivation of $E$. coli 2-oxo-4-hydroxyglutarate aldolase. The experiments were carried out as indicated in the legend to Fig. 1, except that Tris- $\mathrm{HCl}$ was included in the inactivation mixture at the concentrations listed and the assays for aldolase activity were performed at $37^{\circ} \mathrm{C}$. [Tris- $\mathrm{HCl}$ ]: $\Delta, 100 \mathrm{mM} ; \square, 50 \mathrm{mM} ; \mathbf{\square}, 25$ $\mathrm{mM} ; O, 12.5 \mathrm{mM} ; \bullet$, none.

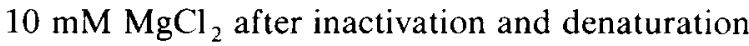
had progressed to completion did not restore activity and had little effect on the subsequent rate of reactivation.

Chloride ion also strongly inhibited denaturation (measured by the decrease in absorbance at $232 \mathrm{~nm}$; see later results) of the acid-treated enzyme even at concentrations which allowed for fairly rapid inactivation. The presence of $3.8 \mathrm{mM}$ Tris- $\mathrm{HCl}$ in enzyme solution adjusted to $\mathrm{pH} 2.15$ slowed the first-order rate of absorbance decrease at $232 \mathrm{~nm}$ from $-0.694 / \mathrm{min}$ to $-0.133 / \mathrm{min}$. In the absence of $\mathrm{Cl}^{-}$, a 20 -fold greater $\mathrm{K}^{+}$concentration was required to cause the same effect.

Protein concentration effects. The rate and extent of acid inactivation and reactivation of aldolase activity was unaffected by enzyme concentrations in the range of 0.1 to $2.3 \mathrm{mg} / \mathrm{ml}$; the process thus appeared to be first-order with respect 
TABLE II

PROPERTIES OF NATIVE, ACID-INACTIVATED, AND REACTIVATED E. COLI 2-OXO-4-HYDROXYGLUTARATE ALDOLASE

Acid-inactivated and reactivated enzyme was prepared and values were determined as described in the text. $V_{\max }$ is expressed as $\mu$ mol of product formed/min per $\mathrm{mg}$ of protein.

\begin{tabular}{|c|c|c|c|c|c|c|}
\hline \multirow[t]{2}{*}{ Enzyme form } & \multirow[t]{2}{*}{$M_{\mathrm{r}}$} & \multicolumn{2}{|c|}{ Kinetic constants } & \multicolumn{2}{|l|}{-SH titer } & \multirow{2}{*}{$\begin{array}{l}\alpha \text {-Helix } \\
\text { content } \\
(\%)\end{array}$} \\
\hline & & $K_{\mathrm{m}}(\mathrm{mM})$ & $\overline{V_{\max }}$ & Exposed & Total & \\
\hline Native & 63000 & 3.45 & 6.25 & 2.0 & 5.4 & 58 \\
\hline Acid-inactivated & 126000 & - & - & 5.1 & 5.1 & 31 \\
\hline Reactivated & 63000 & 3.48 & 3.63 & 2.1 & 4.9 & 56 \\
\hline
\end{tabular}

to enzyme. Addition of bovine serum albumin, ovalbumin, $\gamma$-globulin or human hemoglobin (each at 1 and $10 \mathrm{mg} / \mathrm{ml}$ ) had no significant effect on the rate or extent of inactivation or reactivation.

\section{Properties of acid-inactivated and reactivated al- dolase}

We found that enzyme once reactivated underwent a second cycle of inactivation and reactivation in a pattern virtually identical to the first. After each cycle, about $2 / 3$ of the initial level of aldolase activity was recovered. Some of this loss during repeated cycles was due to the need to dialyze the reactivated enzyme solution after neutralization to decrease the salt concentration.

The electrophoretic pattern of the reactivated enzyme on polyacrylamide gels at $\mathrm{pH} 9.3$ was identical to that of the native enzyme; no additional bands were seen and no loss of sharpness of the single observed band was apparent.

Kinetic parameters. E. coli 2-oxo-4-hydroxyglutarate aldolase routinely exhibits normal hyperbolic kinetics with 2-oxo-4-hydroxyglutarate as substrate. The $K_{\mathrm{m}}$ and $V_{\max }$ of native and reactivated enzyme are shown in Table II. The lowered $V_{\max }$ of the reactivated enzyme reflects the recovery of activity; this was the only property found to be altered for the reactivated enzyme.

Molecular weight determinations. The molecular weights of native, acid-inactivated, and reactivated enzyme are shown in Table II. These values were determined by sedimentation equilibrium and sedimentation velocity centrifugation as well as chromatography on a calibrated column of Sep- hadex. The three methods agreed within $10 \%$ and indicated that the acid-inactivated form of 2-oxo4-hydroxyglutarate aldolase was a dimer of the native enzyme. A small peak of aldolase activity with a molecular weight approximately equal to that of the native enzyme was seen in the Sephadex gel-filtration experiments. The sedimentation experiments were not done so as to analyze critically for paucidispersity but rather to distinguish between subunits $(21000)$, the native enzyme $(63000)$ or higher aggregates. Thus, very small amounts of any one or more of these species might possibly be present in the samples examined.

Sulfhydryl content. Titration of native $E$. coli 2-oxo-4-hydroxyglutarate aldolase with $p$-mercuribenzoate showed the presence of two free sulfhydryl groups per molecule. Addition of $1 \%$ SDS allowed for the titration of three additional groups, or a total of five per molecule [19]. We found that the acid-treated enzyme contained five titratable sulfhydryl groups per molecule of native molecular weight; addition of 1\% SDS had no effect (Table II). The three buried sulfhydryl groups in the native molecule, therefore, appear to become exposed in the acid-inactivated form.

Reactivation of the acid-treated enzyme restored the pattern (free and buried) of titratable sulfhydryl groups to the original state so that the molecule was indistinguishable in this regard from the native enzyme.

Ultraviolet absorption spectra. An ultraviolet-absorbance difference spectrum of the acid-treated enzyme showed minima at 232 and $290 \mathrm{~nm}$ and a 


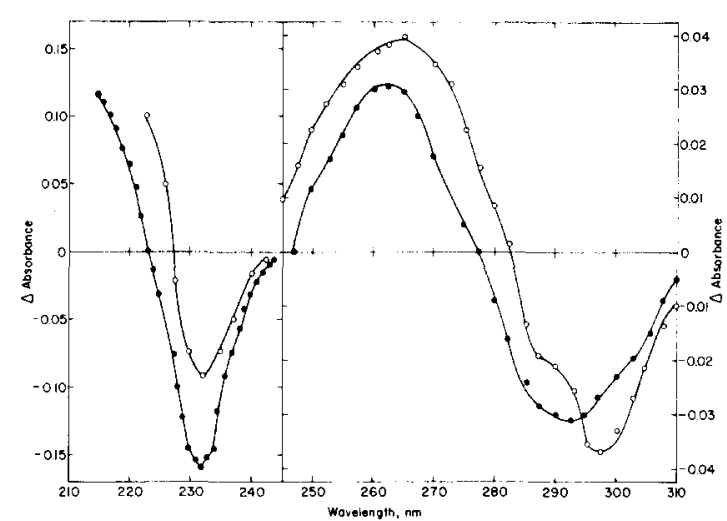

Fig. 3. Ultraviolet absorbance difference spectra of acid-treated minus native $(\bullet)$ and $1 \%$ SDS-denatured minus native $(O) E$. coli 2-oxo-4-hydroxyglutarate aldolase. Protein concentrations used in these measurements were $0.128 \mathrm{mg} / \mathrm{ml}$ for the spectral region of $210-245 \mathrm{~nm}$, and $0.52 \mathrm{mg} / \mathrm{ml}$ for the $245-310 \mathrm{~nm}$ region. Difference spectra were obtained as described in the text.

broad maximum at $263 \mathrm{~nm}$ (Fig. 3). Further hyperchromicity occurred below $220 \mathrm{~nm}$, but this observation was not explored due to increasing absorbance of buffer ions as well as the very strong peptide bond absorbance at such wavelengths. The extrema are in positions which can be assigned to changes in the environment of aromatic aminoacyl residues, although the magnitudes of the changes are larger than can be accounted for by any particular residue even if one assumes that all such residues in the protein contribute.

This difference spectrum is similar to but not identical with that obtained when the enzyme is

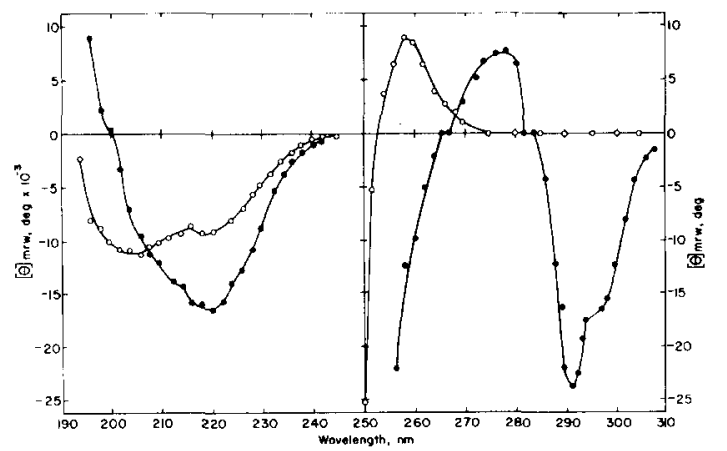

Fig. 4. $\mathrm{CD}$ spectra of native $(\bullet)$ and acid-inactivated $(O) E$. coli 2-oxo-4-hydroxyglutarate aldolase. The spectra were obtained and analyzed as described in the text. denatured by SDS, which treatment we previously determined to cause dissociation of the molecule into its subunits together with exposure of the buried sulfhydryl groups [19]. The major spectral changes observed, therefore, were most likely due to modifications in secondary and tertiary structures of the enzyme; alterations in quaternary structure must contribute little in this regard.

Circular dichroic spectra. CD spectra of native, acid-inactivated, and reactivated enzyme measured in the near and far ultraviolet region are shown in Fig. 4. The far ultraviolet region gives a measure of peptide conformations [20]. The native spectrum indicates a large amount of $\alpha$-helicity with a significant proportion of $\beta$-structure as well. Using the parameters of Chen et al. [20], we calculated that the native structure contains approx. 58\% $\alpha$-helix. Although $\beta$-structure appeared to be about $20-30 \%$, the proportion of this kind of structure and random coil could not be estimated accurately due to the lower ellipticity of $\beta$-structure and random coil as well as the decreased sensitivity of the instrument below $210 \mathrm{~nm}$. The acid-inactivated material showed a significant loss of $\alpha$-helix (31\% remaining, Table II) with a concomitant increase in random coil. Reactivation of the aldolase after acid treatment returned the spectrum to that of the native enzyme when corrected for the amount of activity recovered.

The near ultraviolet absorbance bands can be ascribed to aromatic residues and cysteine disulfides, but we have not attempted to make definite assignments in this region. On acid inactivation of the enzyme, virtually all of the peaks disappeared with the appearance of new positive ellipticity at $258 \mathrm{~nm}$. The negative peak at $290 \mathrm{~nm}$ for the native molecule appears to have a shoulder at a higher wavelength which, on acid treatment of the aldolase, disappeared at a slower rate than the negative and positive peaks at $290 \mathrm{~nm}$ and 278 $\mathrm{nm}$, resp.

Responses to varying $p H$ or temperature. The effect of $\mathrm{pH}$ on the extent of inactivation and reactivation of $E$. coli 2-oxo-4-hydroxyglutarate aldolase is shown in Fig. 5. Inactivation appeared to be slightly greater than first-order with respect to proton concentration, indicating 1 to 2 partially cooperative protonations with a $\mathrm{p} K$ of approx. 3.1. The $\mathrm{pH}$ profile for reactivation of totally inactive 


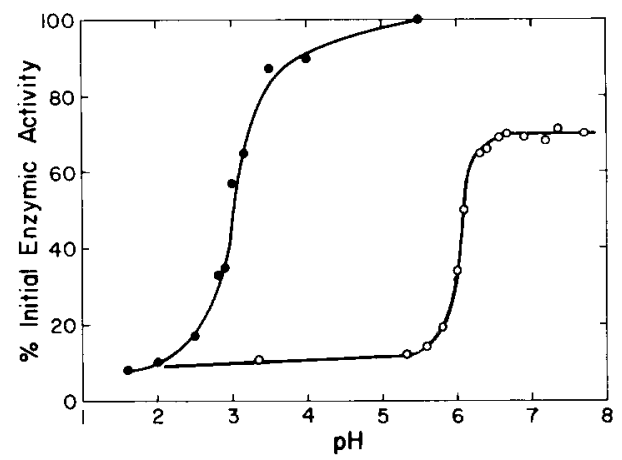

Fig. 5. Effect of $\mathrm{pH}$ on the extent of acid inactivation and reactivation of $E$. coli 2-oxo-4-hydroxyglutarate aldolase. The processes of enzyme inactivation and reactivation were carried out and activity assays were performed as described in the text. Assay temperature was $37^{\circ} \mathrm{C}$. $\bullet$, acid inactivation; $O$, reactivation.
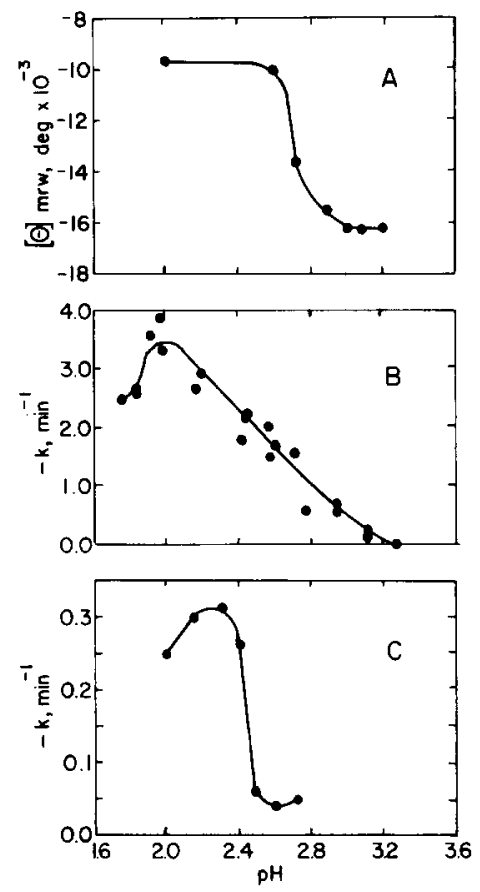

Fig. 6. Effect of $\mathrm{pH}$ and temperature on denaturation of $E$. coli 2-oxo-4-hydroxyglutarate aldolase. A. pH dependence of the mean residue ellipticity at the absorbance minimum of $220 \mathrm{~nm}$ (see Fig. 4), showing the loss of $\alpha$-helical structure at low $\mathrm{pH}$. B. Rate of absorbance change at $232 \mathrm{~nm}$ (see Fig. 3) and $4^{\circ} \mathrm{C}$ as a function of $\mathrm{pH}$. The points plotted are the apparent first-order rate constants. C. Rate of absorbance change at 232 $\mathrm{nm}$ and $15^{\circ} \mathrm{C}$. enzyme has a $\mathrm{p} K$ value of approx. 6 and a slope in the order of 2.7 with respect to $\left[\mathrm{H}^{+}\right]$, suggesting that three interacting protonations are involved in the recovery of activity by the inactivated enzyme. Thus, reactivation of completely inactive enzyme must proceed along a kinetically distinct pathway. However, some reversibility along the $\mathrm{pH}$ curve of inactivation can be seen, i.e., enzyme partially inactivated at $\mathrm{pH} 3$ reactivated almost completely on raising the $\mathrm{pH}$ to $4-5$.

In contrast, the $\mathrm{pH}$ profiles of denaturation, as measured by $C D$ spectral or ultraviolet absorbance changes, are shown in Fig. 6A and B, respectively. It is evident that the apparent $\mathrm{p} K$ values for these changes are lower than the $\mathrm{p} K$ observed for inactivation. Furthermore, the slopes of the corresponding Henderson-Hasselbalch equations indicate approximately a third-order dependence upon $\left[\mathrm{H}^{+}\right]$. As can be seen in Fig. 6B, the rate of absorbance change at $232 \mathrm{~nm}$ upon acidification is approximately first-order with respect to protein absorbance up to about $80 \%$ of the maximum spectral change. Fig. $6 \mathrm{C}$, however, shows that at $15^{\circ} \mathrm{C}$ the maximum rate constant is approximately 0.10 that seen at $4^{\circ} \mathrm{C}$, the apparent $\mathrm{p} K$ is essentially unchanged, but the order of the reaction with respect to $\left[\mathrm{H}^{+}\right]$increases significantly. The rate and extent of enzyme inactivation were also less at $15^{\circ} \mathrm{C}$, so the enzyme exhibits some degree of cold lability at acid $\mathrm{pH}$ values.

\section{Discussion}

2-Oxo-4-hydroxyglutarate aldolase from $E$. coli exhibits an acid-dependent, reversible process of inactivation, denaturation and aggregation. The observed $\mathrm{p} K$ values for the inactivation and denaturation processes are approx. 3.1 and 2.4 , respectively. This range suggests that protonation of carboxylate anions is required for inactivation, although the involvement of a cysteine and/or histidine residue in a unique environment that causes a drastic lowering of its $\mathrm{p} K$ (as, for example, the cysteine residue in papain [21]) cannot be ruled out.

Our data indicate that the process leading to the stable acid form of 2-oxo-4-hydroxyglutarate aldolase must occur via at least two, and more likely three, steps. When the enzyme is exposed to 
an environment of $\mathrm{pH} 3$ or lower, it undergoes a rapid change in tertiary structure leading to loss of enzymic activity followed by an alteration in its secondary structure. On the basis of data currently in hand, it is not possible to assign observed spectral changes specifically to the process of helix-coil transition or aggregation, nor can it be decided whether these are concurrent events or steps in a sequential process. Since the spectral changes appear to be first-order with respect to protein, the simplest interpretation of the observed events would be an initial alteration of secondary structure, followed by a slower association of the altered trimeric protein which does not involve further spectral change.

What meaning and/or significance can be attributed to the acceleration of inactivation and of spectral changes observed for 2-oxo-4-hydroxyglutarate aldolase at lower temperature (i.e., $4^{\circ} \mathrm{C}$ vs. $15^{\circ} \mathrm{C}$ )? In a number of similar cases [22-25], such lability is a consequence of the enzyme's undergoing reversible dissociation at low temperatures $\left(0-10^{\circ} \mathrm{C}\right)$. For phosphofructokinase, acceleration of acid inactivation at low temperature has been attributed to a shift in the $\mathrm{p} K$ of a histidine residue whose protonation is responsible for the inactivation [26]. A different example is glycogen phosphorylase $b$, whose cold lability at $\mathrm{pH} 6.0$, but not at 6.8, apparently is due to association of an inactive species with an active molecule [27].

Kauzmann [28] has attributed cold lability of proteins to the weakening of hydrophobic interactions. Such an explanation is not consistent in this case with the protective effect that ions (specifically $\mathrm{Cl}^{-}$and/or $\mathrm{Mg}^{2+}$ ) and a high ionic environment in general have on enzyme inactivation, and is not consistent with the fact that this aldolase aggregates at low $\mathrm{pH}$. We favor the proposal that low temperatures shift an equilibrium in favor of dimer formation, which would occur if dimerization entails specific ionic interactions and/or hydrogen bonding. Since low temperature accelerates the rate of enzyme inactivation as well as accompanying or subsequent absorbance changes, this explanation requires that the individual steps involved exhibit microscopic reversibility. Preliminary observations indicate in fact that at a $\mathrm{pH}$ near the apparent $\mathrm{pK}$ of inactivation (i.e., $\mathrm{pH}$ approx. 3.2) the spectral change at $232 \mathrm{~nm}$ is thermally reversible.
The protective effect manifested by $\mathrm{Cl}^{-}$against acid inactivation and denaturation of 2-oxo-4-hydroxyglutarate aldolase is unusual. Although high ionic strength alone possibly affords some protection, $\mathrm{Cl}^{-}$is effective at a much lower concentration, suggesting that it is acting in a more specific manner. Moreover, it is considerably more effective in blocking the spectral changes attributed to protein denaturation (which occurs subsequent to inactivation of enzymic activity) than in blocking the inactivation process itself. The $\mathrm{Cl}^{-}$effect on inactivation may, in fact, be due to an inhibition of the denaturation and aggregation processes; this would again require that the inactivation step be reversible. $\mathrm{Cl}^{-}$might prevent denaturation either by replacing a carboxylate anion lost by protonation or by associating with a newly formed cation such as a histidine residue. $\mathrm{Mg}^{2+}$, on the other hand, very likely interacts with the initial site(s) of protonation thereby preventing the inactivation per se. As is evident, however, the effect of $\mathrm{Mg}^{2+}$ has not been explored in detail.

All indications are that reactivation of 2-oxo-4hydroxyglutarate aldolase proceeds via a kinetically distinct pathway since it occurs at a slower rate and at a much higher $\mathrm{p} K$ of approx. 6 . Such a process is consistent with the series of reversible events observed during inactivation, assuming that the final state of the aldolase at pH 1.6 is in a local energy minimum which must be eliminated (i.e., by ionizing groups with a $\mathrm{p} K=6$ ) before the molecule can revert to its true minimum energy state. A mechanism of this type has been described theoretically by Benham and Kozak [29] as a catastrophe process exhibiting the delay convention. We consider it unlikely that the structure of reactivated 2-oxo-4-hydroxyglutarate aldolase is significantly different from the native structure; all properties of the native and reactivated enzyme which have been examined are identical (see Table II).

The acid form of 2-oxo-4-hydroxyglutarate aldolase can be characterized as a hexamer of the basic subunit (i.e., a dimer of the native enzyme). Although there is some alteration of secondary and tertiary structure as evidenced by changes in CD spectra, ultraviolet absorbance spectra and titratable sulfhydryl groups, the molecule must not be highly unfolded, since sedimentation velocity and sedimentation equilibrium determinations of 
the molecular weight of the acid-treated aldolase are in agreement. In contrast, therefore, to cases where exposure to acid causes dissociation, the acid inactivation of $E$. coli 2-oxo-4-hydroxyglutarate aldolase is associated with some modest unfolding and dimerization of the enzyme. This hexameric, inactive form of the enzyme is converted back to the active native configuration by deprotonation of groups with a $\mathrm{p} K$ of approx. 6 .

\section{Acknowledgement}

This research was supported by U.S. Public Health Service Grant AM-03718 from the National Institutes of Health.

\section{References}

1 Maitra, U. and Dekker, E.E. (1963) J. Biol. Chem. 238, 3660-3669

2 Dekker, E.E., Kobes, R.D. and Grady, S.R. (1975) Methods Enzymol. 42, 280-285

3 Kitson, R.P. (1980) Ph.D. Thesis, The University of Michigan

4 Dekker, E.E., Nishihara, H. and Grady, S.R. (1975) Methods Enzymol. 42, 285-290

5 Kobes, R.D. and Dekker, E.E. (1966) Biochem. Biophys. Res. Commun. 25, 329-334

6 Kobes, R.D. and Dekker, E.E. (1971) Biochemistry 10, 388-395

7 Nishihara, H. and Dekker, E.E. (1972) J. Biol. Chem. 247, 5079-5087

8 Hansen, B.A., Lane, R.S. and Dekker, E.E. (1974) J. Biol. Chem. 249, 4891-4896
9 Kobes, R.D. and Dekker, E.E. (1971) Biochim. Biophys. Acta 250, 238-250

10 Wang, J.K., Dekker, E.E., Lewinski, N.D. and Winter, H.C. (1981) J. Biol. Chem. 256, 1793-1800

11 Dekker, E.E. and Maitra, U. (1962) J. Biol. Chem. 237, 2218-2227

12 Kobes, R.D. and Dekker, E.E. (1969) J. Biol. Chem. 244, 1919-1924

13 Ciotti, M.M. and Kaplan, N.O. (1957) Methods Enzymol. 3, 890-899

14 Yphantis, D.A. (1964) Biochemistry 3, 297-317

15 Andrews, P. (1965) Biochem. J. 96, 595-606

16 Riordan, J.F. and Vallee, B.L. (1967) Methods Enzymol. 11, $541-548$

17 Lowry, O.H., Rosebrough, N.J., Farr, A.L. and Randall, R.J. (1951) J. Biol. Chem. 193, 265-275

18 Bradford, M.M. (1976) Anal. Biochem. 72, 248-254

19 Winter, H.C. (1978) Fed. Proc. 37, 1574

20 Chen, Y.H., Yang, J.T. and Chau, K.H. (1974) Biochemistry $13,3350-3359$

21 Lewis, S.D., Johnson, F.A. and Shafer, J.A. (1976) Biochemistry $15,5009-5017$

22 Zumft, W.G. and Mortenson, L.E. (1975) Biochim. Biophys. Acta 416, 1-52

23 Penefsky, H.S. and Warner, R.C. (1965) J. Biol. Chem. 240, 4696-4702

24 Scrutton, M.C. and Utter, M.F. (1965) J. Biol. Chem. 240, 1-9

25 Havir, E.A., Hadassah, T., Ratner, S. and Warner, R.C. (1965) J. Biol. Chem. 240, 3079-3088

26 Bock, P.E. and Frieden, C. (1976) J. Biol. Chem. 251, $5630-5636$

27 Graves, D.J., Sealock, R.W. and Wang, J.H. (1965) Biochemistry 4, 290-296

28 Kauzmann, W. (1959) Adv. Protein Chem. 14, 1-57

29 Benham, C.J. and Kozak, J.J. (1976) J. Theor. Biol. 63 , 125-149 